GAMMA-RAY ENERGIES FOR CALIBRATION OF GE(Li) SPECTROMETERS*

\author{
R. G. Helmer, R. C. Greenwood and R. J. Gehrke
}

Aerojet Nuclear Company, Idaho National Engineering

Laboratory, Idaho Falls, Idaho USA

\title{
INTRODUCTION
}

At the last Conference in this series, we reported (1) on our work in the comparison and measurement of $\gamma$-ray energies with multi channel spectrometer systems using $G(L i)$ detectors. Since that time two things have occurred that are pertinent to the definition of precise calibration energies. First, the 1973 adjustment of the values of the fundamental constants by Cohen and Taylor (2) can be used in place of the values of Taylor et al. (3) of 1969. Second, a number of new precise energy measurements have been made with bent crystal spectrometers. In this paper, we review the existing measurements and our work in this area.

\section{ENERGY SCALES}

In $r$-ray spectrometry, energies have been measured commonly on two different scales. The first group of $\gamma$-ray energies has been measured with respect to the energies, or wavelengths, of the atomic $x$ rays. These data have been (or can be) referred to the $x$-ray energies compiled and correlated by Bearden (4) where the energy scale is referenced to the WKa, $x$ ray. As shown in Table I the newest value of $E\left(W K \alpha_{1}\right)$ is down onily $2.9 \mathrm{ppm}$ from the 1969 value and up $13 \mathrm{ppm}$. from the Bearden value (4)... The reference error in this energy scale is taken to be the $5.6 \mathrm{ppm}$ quoted in ref. 2 for the WKo, energy.

Work performed under the auspices of the U.S. Energy Research :- and Development Adrininistration.

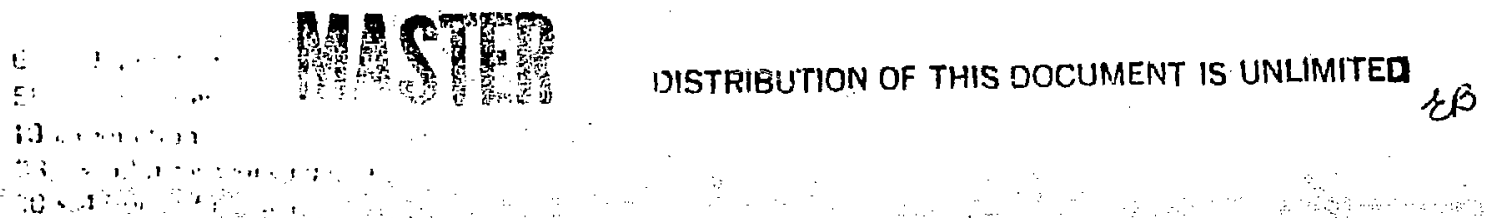


TABLE I

REFERENCE ENERGIES

Value (keV)

\begin{tabular}{|c|c|c|c|c|}
\hline $\begin{array}{l}1967 \\
\text { Bearden }\end{array}$ & $\begin{array}{c}1969 \\
\text { Taylor et al. }\end{array}$ & $\begin{array}{c}1973 \\
\text { Cohen \& Taylor }\end{array}$ & $\frac{\text { Change }}{67-73}$ & $\frac{(\mathrm{ppm})}{69-73}$ \\
\hline \multirow[t]{3}{*}{59.31824} & $59.31918(35)$ & $59.31901(33)$ & +16 & -2.9 \\
\hline & $511.0041(16)$ & $511.0034(14)$ & & -1.4 \\
\hline & $411.794(8)$ & $511.794(7)$ & & \\
\hline
\end{tabular}

The second group of $\gamma$-ray energies have been measured with respect to a scale based on the energy equivalent of the mass of the electron, $m_{0} c^{2}$. As indicated in Table $I$, the latest value of $\mathrm{m}_{0} \mathrm{c}^{2}$ is reduced by oniy $1.4 \mathrm{ppm}$ from the previous value. The basic measurement on this energy scale is the single determination $(5,6)$ of the energy of the 411-keV line from the decay of 193 Au relative to the $m_{0} c^{2}$ value as observed in positronium annihilation. For this line, the current error is $7 \mathrm{eV}$ or $17 \mathrm{ppm}$ which is taken to be the reference error in this scale.

Several measurements have been made to determine the consistency of the two energy scales, with varying results. This question will be discussed in another paper at this Conference (7). We have chosen not to make any adjustments between the energies measured on the two scales.

In all cases a distinction has been made between two components of the energy uncertainty: (1) the contribution from the reference energy defining the energy scale, $\sigma_{r}$, and (2) that from the specific measurements $\sigma_{m}$, and $\sigma_{t}^{2}=\sigma_{r}^{2}+\sigma_{m}^{2}$.

\section{GAMMA-RAY ENERGIES}

\section{Comparison of Recent Bent Crystal Measurements}

For primary calibration for our $\gamma$-ray energy measurements on $\mathrm{Ge}$ (Li) spectrometers, a set of precisely known $\gamma$-ray energies, measured by other techniques, was compiled. Besides having the necessary precision, only those data were included which were available with sufficient detail to allow reevaluation to correspond to the current set of fundamental constants.

Of special interest are two groups of recent precise measurements (8-11) relative to the Au-411 line made with bent-crystal (diffraction) spectrometers. Some of these new values are quoted 
with very high precision; for examile, $\tau_{\mathrm{m}}=0.06$ and $0.4 \mathrm{eV}$ at 100 and $200 \mathrm{keV}$. For the energies of $192 \mathrm{Ta}$ and $192 \mathrm{Ir}$ a comparison is given in Table 11.- of the 20 entries, the agreement is not quite within the quoted errors since 12 differences are over 10 , five are over 20 and three are over $4 \sigma$. At this level of precision. this agreement may be quite reasonable. However, it should be noted that for many 1 ines the uncertainty in the discrepancy comes primarily from the work of Kern et al. (8-9) and as a result, does not indicate whether the Borchert et al. $(10,11)$ errors are realistic.

These data also indicate that for $182 \mathrm{Ta}$ any systematic difference is quite small while for 192 ir the Borchert et al. values are larger by 5-10 ppm.

TABLE II

COMPARISON OF RECENT BENT-CRYSTAL MEASUREMENTS

\begin{tabular}{|c|c|c|c|c|}
\hline $\begin{array}{l}\text { Parent } \\
\text { Isotope }\end{array}$ & $\begin{array}{l}\text { Energy } \\
(\mathrm{kev})\end{array}$ & \multicolumn{2}{|c|}{ Uncertainty } & $\begin{array}{c}\text { Difference } \\
(\mathrm{eV})\end{array}$ \\
\hline${ }^{182} \mathrm{Ta}$ & $\begin{array}{r}65 \\
67 \\
100 \\
113 \\
152 \\
156 \\
179 \\
198 \\
222 \\
229 \\
264\end{array}$ & $\begin{array}{l}0.2 \\
0.2 \\
0.3 \\
1.2 \\
1.4 \\
1.2 \\
1.8 \\
2.2 \\
2.4 \\
3.0 \\
5.2\end{array}$ & $\begin{array}{l}0.15 \\
0.13 \\
0.06 \\
0.26 \\
0.27 \\
0.35 \\
0.53 \\
0.44 \\
0.45 \\
0.63 \\
0.61\end{array}$ & $\begin{array}{r}1.1 \pm 0.3 \\
1.3 \pm 0.2 \\
2.7 \pm 0.3 \\
-2.3 \pm 1.2 \\
1.7 \pm 1.4 \\
-1.6 \pm 1.3 \\
0.5 \pm 1.9 \\
0.6 \pm 2.2 \\
-2.6 \pm 2.4 \\
0.0 \pm 3.1 \\
2.0 \pm 5.2\end{array}$ \\
\hline & & Beer (9) & Borchert (11) & \\
\hline $192 \mathrm{Ir}$ & $\begin{array}{l}136 \\
295 \\
308 \\
316 \\
416 \\
468 \\
588 \\
604 \\
612\end{array}$ & $\begin{array}{l}0.7 \\
1.5 \\
1.7 \\
1.5 \\
5 . \\
4 . \\
8 . \\
8 . \\
9 .\end{array}$ & $\begin{array}{l}0.7 \\
0.5 \\
2.2 \\
0.3 \\
3.0 \\
0.6 \\
4.0 \\
2.2 \\
2.6\end{array}$ & $\begin{array}{r}-0.5 \pm 1.0 \\
-2.4 \pm 1.6 \\
-0.6 \pm 2.8 \\
-2.3 \pm 1.6 \\
-8.1 \pm 5.8 \\
-8.2 \pm 4.0 \\
-22.0 \pm 8.9 \\
-2.1 \pm 8.3 \\
-5.3 \pm 9.4\end{array}$ \\
\hline
\end{tabular}




\section{Energy from Other Authors}

Our treatment of data in the literature is illustrated for the case of 192 Ir. The data used here for these $\gamma$-ray energies are Indicated at the bottom of Table-III along wi th the type of instrument used and the reference line. The various energies for one line were averaged ( $1 / 0$ wejghting). These average values were then used as input to a least-squares fitting program which deternines the "best" level energies for the decay scheme. The "best" $\gamma$-ray energies and uncertainties were then computed from these level energies.

In addition to these $\gamma$-ray energy values, the input to this partic"lar least-squares determination of the level energies included two $\gamma$-ray energy differences. These were our measured 588-604 and 588-612 differences. The inclusion of these differences is significant in that it increases directly the energy of the 583keV line by $3 \mathrm{eV}$ and indirectly the 416 - and 884-keV energies. The average energies are quite consistent since the reduced- $x^{2}$ of the least-squares fit is 0.60 . This is in contrast to the various experiments which are somewhat inconsistent as indicated by the reduced $-x^{2}$ values for the averages.

TABLE III

192 Ir GAMMA ENERGIES

Average Error (eV) Reduced- $x^{2}$

0.5

0.8

1.3

2.4

1.0

3.7

1.3

6.6

2.6

3.0

24.0
0.3

1.8

4.4

3.4

4.9

1.9

2.2

3.2

0.4

0.7

$-\infty$

Author

Murray et a 1. (6) Daniel et al. (12)

Reidy ( $\overline{13})$

Helmer et al. (14)

Inove et at. (15)

Beer \&ern (9)

Borchert et al.

Least-Squares

Value (kev)

136.3398

205.7903

- 295.9496

308.4491

316.4994

416.4602

468.0588

588.5692

604.3982

612.4485

884.5179 $\frac{\text { Uncertainty }(\mathrm{eV})}{\text { Measurement } \text { Total (Au) }}$

0.5

2.4

0.8

1.0

1.1

0.9

1.4

1.0

1.1

1.0

3.6

5.1

5.3

5.5

7.2

8.1

10.1

1.0

10.3

1.8
10.5

15.1

Date Ref. Line Spectrometer No. Energies

1965

1966

1970

1971

1973

1974

(11) 1975

Electron

Electron

Bent-crystal

$\mathrm{Ge}$ (Li)

Ge(Li)

Au-411 Bent-crystal 10

Au-411 Bent-crystal 10

7

1

5

2

1 
In this manner we have evaluated the $r$ way energies for a number of isotopes including only bent-crystal and electron spectrometer measurements. The recent measurements (8-11) for $192 \mathrm{Ir}$ and $183 \mathrm{Ta}$ and the low-energy $182 \mathrm{Ta}$ lines have been combined with earlier data and evaluated by the above nethods including a leastsquares fit to the level scheme. In addition to these three isotopes, we have included energies from 12 other isotopes and a total of 21 lines.

\section{Our Measuremints}

The goal of our measurements of $y$-ray energies has been to extend the above set of calibration energies, especially above 400 keV. A?l of our measurements have been made on $\mathrm{Ge}$ (Li) spectrometers. In a few cases, our energies have been determined simply by determining the energy of a peak from spectra calibrated with several known lines. More generally our ineasurements have been of the difference in energy between closely spaced lines, one of which has a "known" energy. This method is used for two reasons. First, highly accurate differences can be obtained on $\mathrm{Ge}(\mathrm{Li})$ spectrometers in spite of their inherent nonlinearity and ill-defined "zero". Second, the values of the energy differences are independent of small changes in the calibration energies and, therefore, can be updated as the primary calibration energies chañge.

In many cases, cascade-crossover relationships have been used to compute the energy of one of the transitions involved. in particular, two chains of energy combinations have been developed separately up to above $1 \mathrm{MeV}$ as shown in Fig. 1. One chain consists of the lines from $192 \mathrm{Ir}$ and $160 \mathrm{~Tb}$ and the other consists of $198 \mathrm{Au}$, $5 \mathrm{~F} F \mathrm{fe}$ and ${ }^{182} \mathrm{Ta}$. As indicated in the figure, precise comparisons between the two chains can be made to indicate the magnitude of potential systematic errors. In computing the uncertainties in the discrepancy, the 884-(192 Ir) and 1087-keV (198Au) energies have first been assumed to be exact. Thus, the first error includes only the measurement uncertainties above these points in the chains. The average discrepancy for two comparisons is $(11 \pm 4) \mathrm{eV}$. On the bas is of this result, we might conclude that there is a sma1l, real discrepancy between the energies of the two chains at above $1 \mathrm{MeV}$. However, if one includes the measurement errors in the 884 ( $192 \mathrm{Ir}$ ). and 1087 (198Au) energies, the average discrepancy becomes $(11 \pm 12)$ eV. This result indicates that this discrepancy is not unreasonable compared to the magnitude of the measurement errors. The major contribution to this $12 \mathrm{eV}$ measurement error is the $11 \mathrm{eV}$ term from the 675-keV line of ${ }^{198} \mathrm{Au}$.

At $1 \mathrm{MeV}$ typical errors are $\sigma_{\mathrm{m}}=4, \sigma_{\mathrm{r}}=17$ and $\sigma_{t}=17 \mathrm{eV}$ for $\checkmark$ rays based on the ${ }^{192}$ Ir-884 line and $\sigma_{m}=11, \sigma_{r}=17$ and $\sigma_{t}=20 \mathrm{eV}$ for those based on the $198 \mathrm{Au}-1087$ line? 


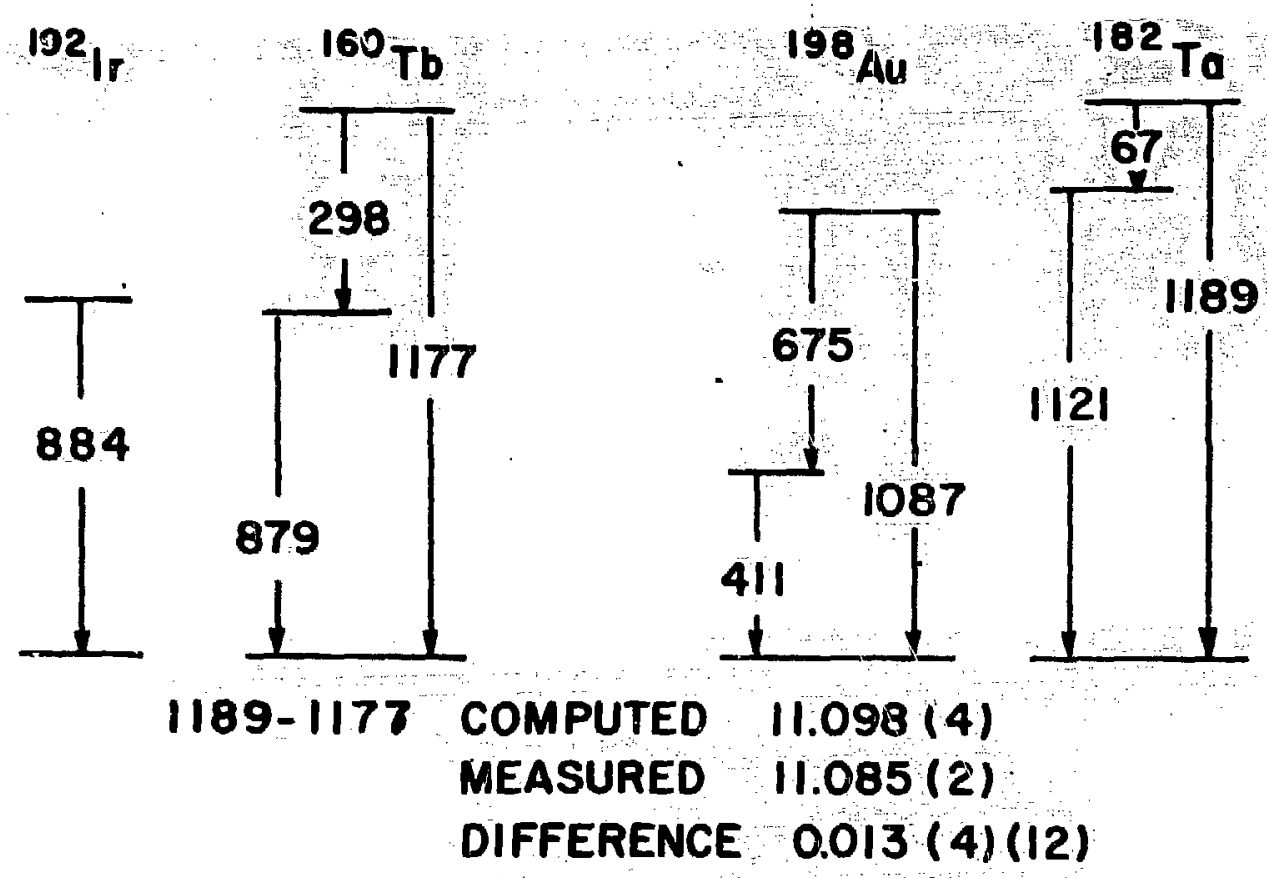

Fig. 1. Gamma-ray energy differences and sums jnvolved in going from $192 \mathrm{Ir}-884$ to $160 \mathrm{~Tb}-1177$ and from $198 \mathrm{Au}-411$ to $182 \mathrm{Ta}-1189$; and the results of comparing the $160 \mathrm{~Tb}-1177$ and $182 \mathrm{Ta}-1189$ energies.

\section{- COMMENTS}

In summary, based on the primary calibration energies from other types of spectrometers, our energy differences and energy combinations have been used to determine the energies of 150 y rays below $3450 \mathrm{keV}$ from 35 isotopes. The energies of 79 lines below. $1300 \mathrm{keV}$ have been published $(14,16)$, but these have recentiy been reevaluated based on the new fundamental constants and the riew bent-crystal measurements.

For the above treatment of $\gamma$-ray energies, the single measurement that would be the most effective in improving the existing energies would be a more precise comparison of the energy of the $675-\mathrm{keV}$ line from ${ }^{198 \mathrm{Au}}$ to that of the $411-\mathrm{keV}$ line of $198 \mathrm{Au}$.

Another significant improvement would result from a more accurate measurement of the $411-\mathrm{keV}$ energy from $19{ }^{8 \mathrm{Au}}$. For example, in Table III the $884-\mathrm{keV}$ line from ${ }^{198}$ Ir has a total uncertainty of 
$15 \mathrm{eV}$, but a measurement error of only $2 \mathrm{eV}$. So a very precise (error of $\sim 1 \mathrm{eV}$ ) $411-\mathrm{keV}$ energy would make a vast improvenient. If this were combined with a comparable measurement of the $675-\mathrm{keV}$ line of $198 \mathrm{Au}$, one would have both energy chains with errors at 1 MeV of a felveV.

In contrast to the last Conference, we have not discussed the techniques used in Ge(Li) spectronietry. It should only be noted that on $G e(L i)$ detectors the apparent energy does depend on the source position. We have reported (17) measurements on the shift of peak positions with the source-detector distance, with observed shifts as large as $100 \mathrm{eV}$ for a $2000 \mathrm{keV}$ Y ray.

\section{REFERENCES}

1. HELMER, R. G., GREENHOOD, R. C., and GEHRKE, R. J., Atomic Masses and Fundamental Constants 4 , eds. J. H. Sanders and A. H. Wapstra, Plenum Press (London) 1972.

2. COHEN, E, R. and TAYLOR, B. H., J. Phys. Chem. Ref. Data? (1973) 663.

3. TAYlOR, B. N., PARKER, W. H., and LANGenBerG, D. N., Rev. Mod. Phys. 41 (1969) 375.

4. BEARDEN, J. A., Rev. Mad. Phys . 39 (1967) 78.

5. MURRAY, G., GRAHAM; R. L. and GETGER, J. S., Nucl. Phys. 45 (1963) 177.

6. MUURRAY, G., GRAHAM, R. L. and GEIGER, J. S., Nucl. Phys. 63 (1965) 353 .

7. VAN ASSCHE, P. H. M., BORNER, H., DAVIDSON, W., KOCH, H. R., and PINSTON, J. A., a paper presented at this Conference.

8. PILLER, 0., BEER, $W$. and KERN, J., Nucl. Instr. and Meth. 107 (1973) 61 .

9. BEER, W. and KERN, J., Nucl. Instr. and Meth. 117 (1974) 183.

10. BORCHERT, G. L., SCHECK, H. and SCHULT, O. H. B.s NuCl. Instr. and Meth. 124 (1975) 107.

11. BORCHERT G. L., SCHECK, W. and WIEDER, K. P., Zeits für Naturforsch. 30a (1975) 274.

12. DANIEL, H., JAHN, P. and TODT, W., Bul1. Akad. Sci. USSR, Phys. Ser. 30 (1966) 2107.

13. REIDY, J. J., private communication.

14. HELMER, R. G., GREENWOOD, R. C., and GEHRKE, R. J., Nuc1. Instr. and Meth. 96 (1971) 1973.

15. INOUE, $H_{\text {. }}$ and YOSHIZAWA, $Y$, Nucl. Instr. and Meth. 108 (1973) 385.

16. GREENWOOD, R. C., HELMER, R. G., and GEHRKE, R. J., Nucl. Instr. and Meth. 77 (1970) 141.

17. HELMER, R. G., GEḦRKE, R. J., and GREENWOOD, R. C., NUC1. Instr. and Meth. 123 (1975) 51. 